ScIDice

\section{International Journal of Dentistry and Oral Science (IJDOS) \\ ISSN: 2377-8075}

\title{
Obstructive Sleep Apnea - A Review
}

Review Article

\section{Melvin George ${ }^{1}$, Madhulaxmi Marimuthu ${ }^{2 *}$}

${ }^{1}$ Fellow in Orthognathic Surgery, Department of Oral and Maxillofacial Surgery, Saveetha Dental College and Hospitals, Saveetha Institute of Medical and Technical Sciences, Saveetha University, Poonamallee High Road, Vellappanchavadi, Chennai, Tamil Nadu, India.

${ }^{2}$ Professor, Department of Oral and Maxillofacial Surgery, Saveetha Dental College and Hospitals, Saveetha Institute of Medical and Technical Sciences, Saveetha University, Poonamallee High Road, Vellappanchavadi, Chennai, Tamil Nadu, India.

\section{Abstract}

Obstructive sleep apnea (OSA) is a common sleeping disorder. As the name suggests, it is associated with apneic and hypopneic breathing due to some kind of obstruction in the respiratory passage and thereby interferes with sleep. This review aims to give a concise overview on the disease, its pathophysiology, clinical presentation, diagnosis and various methods of management.

Keywords: Obstructive Sleep Apnea; Airway; Polysomnography; Medical; Surgical; Management.

\section{Introduction}

Obstructive sleep apnea (OSA) is an increasingly common, chronic sleep-related breathing disorder which is characterized by periodic narrowing and obstruction of the pharyngeal airway during sleep [1, 2]. Untreated OSA can be associated with metabolic disorders, cardiovascular disease, cognitive impairement, depression, loss of productivity in workplace and motor vehicle accidents [3]. The causes and consequences of OSA vary between patients. Most patients with OSA are undiagnosed and untreated which might be related to lack of awareness about the disorder [4, 5]. Early detection of OSA can result in greatly improved quality of life along with reduction of systemic morbidities.

\section{Pathophysiology}

OSA is characterized by recurrent collapse of pharyngeal airway during sleep, resulting in substantially reduced or complete cessation of airflow despite ongoing breathing efforts These disturbances lead to intermittent hypercapnia and hypoxia and surges in sympathetic activation. The culmination of a respiratory event leads to brief awakening from sleep. These events result in a cyclical breathing pattern and fragmented sleep as the patient oscillates between wakefulness and sleep. Each respiratory event can last 20 to 40 seconds [6].

During wakefulness, OSA patients compensate for compromised airway through protective reflexes to increase upper airway dilator muscle activity to maintain patency of airway [7]. Obstructive sleep apnea occurs due to anatomic factors that cause pharyngeal narrowing which include large neck circumference, cervical soft tissue, vessels and bony structures. Many of these factors cause pharyngeal collapse by decreasing the caliber of the upper airway or by increasing the upper airway surrounding pressurewhich happens during Rapid Eye Movement (REM) sleep when protective reflexes to maintain upper airway is lost, leading to a period of hyponea or apnea [8].

\section{Clinical Manifestation}

Symptoms of OSA include, snoring, excessive daytime sleepiness, choking or gasping at night, night sweats, neurocognitive impairment, heartburn, morning headaches, maintenance insomnia, erectile dysfunction and nocturia [9]. Snoring due to redundant pharyngeal muscles can be an early symptom of OSA. This proceeds to episodes of apnea leading to excessive daytime sleepiness which is usually the first complaint given by the patient. These patients become somnolent in passive situations or during monotonous activities such as watching television, reading books, or

\section{*Corresponding Author:}

Madhulaxmi Marimuthu MDS,

Professor, Department of Oral and Maxillofacial Surgery, Saveetha Dental College and Hospitals, Saveetha Institute of Medical and Technical Sciences, Saveetha University, No 162 , Poonamallee High Road, Vellappanchavadi, Chennai-600077, Tamil Nadu, India.

Tel: +91-73738-14000

E-mail: madhulaxmi@saveetha.com

Received: July 25, 2020

Accepted: September 11, 2020

Published: October 08, 2020

Citation: Melvin George, Madhulaxmi Marimuthu. Obstructive Sleep Apnea - A Review. Int J Dentistry Oral Sci. 2020;7(10):849-851. doi: http://dx.doi.org/10.19070/2377-8075-20000167

Copyright: Madhulaxmi Marimuthu 2020 . This is an open-access article distributed under the terms of the Creative Commons Attribution License, which permits unrestricted use, distribution and reproduction in any medium, provided the original author and source are credited. 
during a long drive. If the aforementioned problem occurs despite getting adequate amount of sleep during the preceding night the patient may have a problem with quality of his/her sleep [10]. The symptoms of OSA are the result of sleep disturbance which will in most cases be unnoticed by the patient.

Clinical fiindings in OSA patients will be obesity, enlarged neck circumference, crowded upper airway, hypertension, accentuated P2 heart sounds, retrognathia, nalsa obstruction, decreased oxygen saturation, S3 heart sound, lower extremity edema (heart failure) $[9]$.

\section{Diagnosis of OSA}

The clinician should search for clinical features that are listed in Epworth Sleepiness Scale Questionnaire. Having $\geq 2$ of those symptoms indicate the need for further assessment or a sleep study.

The patient should choose one of the 0-3 numbers as described below in the recent two weeks. Scores greater than 10 out of 24 are regarded as presence of daytime sleepiness.

\section{Polysomnography}

Overnight polysomnography is the gold-standard diagnostic test for OSA. Patients who are diagnosed with OSA and choose continuous positive airway pressure (CPAP) therapy are then brought back for follow up study, during which the pressure of CPAP device is titrated. Alternatively those two studies can be done in selected patients over one night, followed by a "split-night protocol". The two parts of the split night study complement each other; diagnosis of OSA is made during the first part, followed by titration of CPAP during the second half of the study. If there are more than 20 respiratory events per hour in the first half of the study in a patient with a high pre-test probability (having two or more clinical features), or $\geq 40$ respiratory events in a patient with a pretest low-probability, splitting the study is recommended. Starting CPAP titration during the same night sleep study is timeand cost effective while expediting delivery of treatment to the patients. It should be noted that the first half of the split night sleep study has to have at least 2 hours of recorded sleep data.

A negative polysomnogram does not exclude diagnosis of OSA particularly in high-risk patients. In such patients repeating the polysomnogram should be considered.

\section{Portable monitoring}

There are a variety of devices that are used for in-home, portable monitoring of cardiorespiratory parameters. An effective portable monitor requires at least three channels to asses airflow, thoracoabdominal movements, and blood oxygenation [12]. In general the sensitivity and specificity of these devices seem to be high in populations at high risk for OSA assuming there are no other comorbid medical or sleep disorders. Clinical practice guidelines from the American Academy of Sleep Medicine (AASM) indicate that portable monitoring may be used as an alternative to polysomnography to diagnose OSA in patients with a high pretest probability of moderate to severe OSA [13]. Portable monitoring should not be used if another sleep disorder is suspected or the patient has comorbid medical conditions that predispose to non-OSA sleep related breathing disorders. These comorbid conditions include, but are not limited to, moderate to severe pulmonary diseases, neuromuscular diseases, congestive heart failure, movement disorders, parasomnias, sleep seizures, etc.

Table. Shows the Epworth Sleepiness Scale Questionnaire.

\begin{tabular}{|l|c|}
\hline 0 & would never doze or sleep. \\
\hline 1 & slight chance of dozing or sleeping \\
\hline 2 & moderate chance of dozing or sleeping \\
\hline 3 & bigh chance of dozing or sleeping \\
\hline & Sitting and reading \\
\hline & Watching TV \\
\hline & Sitting inactive in a public place \\
\hline & Being a passenger in a motor vehicle for an hour or more \\
\hline & Lying down in the afternoon \\
\hline & Sitting and talking to someone \\
\hline & Sitting quietly after lunch (no alcohol) \\
\hline
\end{tabular}

Evaluations used in sleep test [11]

\begin{tabular}{|c|c|}
\hline Level 1 & In-laboratory, technologist attended polysomnography \\
\hline Level 2 & Full (unattended) polysomnography \\
\hline Level 3 & Portable monitoring with three or more channels, including pulse oximetry and heart rate \\
\hline Level 4 & Portable monitoring with only one or two channels including pulse oximet \\
\hline
\end{tabular}




\section{Treatment}

\section{Continuous positive airway pressure}

Continuous PAP (CPAP), generally administered through the nose (nCPAP), is undoubtedly considered the gold standard treatment for OSA. Since its invention in 1983 by Dr Sullivan, the clinical application of this device has deeply modified the course of the disease over the last three decades, offering to thousands of patients the first noninvasive method to control their disorder [14]. Worldwide, nCPAP is constantly recommended as the firstchoice treatment for patients with moderate to severe OSA.

\section{Positional Therapy}

The supine position, mainly due to the effect of the gravity on tongue and soft palate position, is generally associated with an increased number of apnoeas/hypopnoeas.

If postural OSA is diagnosed, patients can benefit from a positional therapy (PT), which should prevent them from sleeping in the supine posture. Many PT strategies are available. These include the simple 'tennis ball technique', consisting of a tennis ball strapped to the back to discourage supine position, supine alarm devices and a number of positional pillows [15].

\section{Oral Appliances}

The most commonly used oral appliances are mandibular advanced splints (MAS). These devices attach to both the upper and lower dental arches in order to advance and retain the mandible in a forward position. This will relocate laterally the pharyngeal fat pads from the airway and the tongue base will move forward. Consequently, the upper airway will be widened, particularly in its lateral dimension, and the function of upper airway dilator muscles, particularly the genioglossus, will improve.

\section{Surgical management}

Patients with OSA generally have excessive tissue in the oropharyngeal tract. Uvulo-palatopharyngoplasty (UPPP), either conventional or laser assisted (LAPP), is a widely established surgical procedure for the treatment of OSA in selected patients. This technique consists of the resection of uvula, part of the soft palate and tissue excess in the oropharynx, and is usually performed with simultaneous tonsillectomy.

Maxillomandibular advancement (MMA) is obtained by osteotomy of the maxilla and mandibular. The advancement of the skeleton structures passively induces an anterior displacement of the soft palate and the tongue with a simultaneous widening of the pharyngeal space.

\section{Weight control}

Obesity is an important risk factor for OSA and over $70 \%$ of patients with OSA have obesity; a strict correlation has been docu- mented between body mass index (BMI) and AHI. Weight loss is therefore a main goal in the management OSA and all patients should be encouraged to control their weight. Bariatric surgery offers a good option of weight loss if conventional methods fail.

\section{Educational and behavioural intervention}

Educational and behavioural interventions represent the first step in approaching patients with OSA, independently from the treatment chosen. Patients should be instructed to avoid risk factors such as smoking, drinking alcohol (particularly in the evening), using sedatives and hypnotics.

\section{References}

11. Heinzer R, Vat S, Marques-Vidal P, Marti-Soler H, Andries D, Tobback N et al. Prevalence of sleep-disordered breathing in the general population: the HypnoLaus study. Lancet Respir Med. 2015 Apr;3(4):310-8. PubmedPMID: 25682233.

[2]. Punjabi NM. The epidemiology of adult obstructive sleep apnea. Proc Am Thorac Soc. 2008 Feb 15;5(2):136-43. PubmedPMID: 18250205.

[3]. Osman AM, Carter SG, Carberry JC, Eckert DJ. Obstructive sleep apnea: current perspectives. Nat Sci Sleep. 2018 Jan 23;10:21-34. PubmedPMID: 29416383.

[4]. Appleton SL, Vakulin A, McEvoy RD, Vincent A, Martin SA, Grant JF, et al. Undiagnosed obstructive sleep apnea is independently associated with reductions in quality of life in middle-aged, but not elderly men of a population cohort. Sleep and Breathing. 2015 Dec 1;19(4):1309-16.

[5]. Simpson L, Hillman DR, Cooper MN, Ward KL, Hunter M, Cullen S, et al. High prevalence of undiagnosed obstructive sleep apnoea in the general population and methods for screening for representative controls. Sleep Breath. 2013 Sep;17(3):967-73. PubmedPMID: 23161476.

[6]. Eckert DJ, Malhotra A. Pathophysiology of adult obstructive sleep apnea. Proc Am Thorac Soc. 2008 Feb 15;5(2):144-53. PubmedPMID: 18250206.

[7]. Mezzanotte WS, Tangel DJ, White DP. Waking genioglossal electromyogram in sleep apnea patients versus normal controls (a neuromuscular compensatory mechanism). J Clin Invest. 1992 May;89(5):1571-9. Pubmed PMID: 1569196.

[8]. Sankri-Tarbichi AG. Obstructive sleep apnea-hypopnea syndrome: Etiology and diagnosis. Avicenna J Med. 2012 Jan;2(1):3-8. PubmedPMID: 23210013.

[9]. Stansbury RC, Strollo PJ. Clinical manifestations of sleep apnea. J Thorac Dis. 2015 Sep;7(9):E298-310. PubmedPMID: 26543619.

[10]. Foroughi M, Razavi H, Malekmohammad M, AdimiNaghan P, Jamaati H. Diagnosis of Obstructive Sleep Apnea Syndrome in Adults: A Brief Review of Existing Data for Practice in Iran. Tanaffos. 2016;15(2):70-74. Pubmed PMID: 27904537.

[11]. Canadian Sleep Society, Blackman A, McGregor C, Dales R, Driver HS, Dumov I, et al . Canadian Sleep Society/Canadian Thoracic Society position paper on the use of portable monitoring for the diagnosis of obstructive sleep apnea/hypopnea in adults. Can Respir J. 2010 Sep-Oct;17(5):229-32. PubmedPMID: 21037998.

[12]. Collop NA, Tracy SL, Kapur V, Mehra R, Kuhlmann D, Fleishman SA, et al. Obstructive sleep apnea devices for out-of-center (OOC) testing: technology evaluation. J Clin Sleep Med. 2011 Oct 15;7(5):531-48. PubmedPMID: 22003351.

[13]. Collop NA, Anderson WM, Boehlecke B, Claman D, Goldberg R, Gottlieb DJ, et al. Portable Monitoring Task Force of the American Academy of Sleep Medicine. Clinical guidelines for the use of unattended portable monitors in the diagnosis of obstructive sleep apnea in adult patients. Portable Monitoring Task Force of the American Academy of Sleep Medicine. J Clin Sleep Med. 2007 Dec 15;3(7):737-47.Pubmed PMID: 18198809.

[14]. Sullivan CE, Berthon-Jones M, Issa FG. Nocturnal nasal-airway pressure for sleep apnea. N Engl J Med. 1983 Jul 14;309(2):112.PubmedPMID: 6343875.

[15]. Frank MH, Ravesloot MJ, vanMaanen JP, Verhagen E, de Lange J, de Vries N. Positional OSA part 1: Towards a clinical classification system for positiondependent obstructive sleep apnoea. Sleep Breath. 2015 May;19(2):473-80. Pubmed PMID: 24943728. 